\title{
Flood Management and Geoinformation Support within the Emergency Cycle (EU Example)
}

\author{
Petr Kubíček ${ }^{1}$, Eva Muličková ${ }^{1}$, Milan Konečný ${ }^{1}$, and Jitka Kučerováa \\ ${ }^{1}$ Department of Geography, Masaryk University of Brno, \\ Kotlarska 2, 61137 Brno, Czech Republic \\ \{kubicek, mulickova, konecny\} @geogr.muni.cz \\ ${ }^{2}$ Czech Hydrometeorological Institute, Kroftova 43, 61667 Brno, Czech Republic \\ jitka.kucerova@chmi.cz
}

\begin{abstract}
Paper describes the state-of-the-art of flood management both in the Czech Republic and in the broader framework of EU. Special focus is given to geoinformation and cartographic issues within consecutive parts of emergency management cycle used in European Union countries (prevention, preparation, response, and recovery phases). For each phase an adaptive mapping solution is outlined. The principles of adaptive cartography and its applications are described.
\end{abstract}

Keywords: Floods, geoinformation, adaptive mapping, context.

\section{Introduction}

The goal of crisis management activities is to reduce the degree to which a community condition is worsened by a disaster relative to its pre-disaster condition [2]. The field of crisis management usually divides any situation into four components (phases) that roughly correspond to the before - called preparedness, during - called response, and after phase (recovery) of any particular event. The last but not least mitigation (and prevention) phase is concerned with minimizing the effects of possible disasters by mandating policies and regulations that will lessen the effects of hypothetical disaster. Each of these phases put particular demands on emergency managers and responders, and each can be informed and improved by the application of geospatial data and tools. These phases follow one another in a continuous cycle, with a disaster event occurring between preparedness and response phase (Fig.1). Geospatial demands vary across the phases of disaster as well as across hazard types. Geospatial resources and processes thus must be able to adapt and respond to follow the changing demands.

In the case of crises management geospatial services can provide a unified environment allowing visualizing, analyzing, and/or editing data from various data sources within a single client. The main theoretical approach proposed for the crises management cartographic support is so called adaptive cartography. This method is based on the idea of geodata visualization automation and adjustment according to situation, purpose and user's background $[9,10,8]$. Adaptive maps are still supposed to be maps, i.e. correct, well legible, visual medium for spatial information transmission. 
While all map modification processes are incorporated in electronic map logic, users can affect adaptive map just indirectly by a context.

Geospatial demands vary across the phases of disaster as well as across hazard types. Geospatial resources and processes thus must be able to adapt and respond to follow the changing demands. In order to document the adaptation process we are presenting the example of flood management and proposing the cartographic contexts and possible data sources for particular phases of disaster management cycle. Remainder of the text is structured as follows: Chapter 2 brings overview of flood management in the Czech Republic - it describes its legal framework and points out some activities and responsibilities. Chapter 3 analyses the current flood (geo)information resources according to the phase of the flood situation it relates to. Chapter 4 describes the adaptive mapping approach applied to the flood and defines selected contexts.

\section{Flood Management in the Czech Republic}

The causes and consequences of flood events vary across the countries and regions of Europe. Flood risk management should therefore take into account the particular characteristics of the areas and ensure relevant coordination within river basin districts and promote the achievement of environmental objectives. This fact led to the establishment of Directive 2007/60/EC of the European parliament and of the council of 23 October 2007 on the Assessment and Management of Flood Risks [4]. Based on this directive member states shall make available to the public flood relevant documents and information - namely the preliminary flood risk assessment, the flood hazard maps, the flood risk maps and the flood risk management plans.

For each type of documents the following is then recommended:

- The preliminary flood risk assessment - states, for which part of river basin district, the flood risk assessment will be accomplished. Only selected river basin areas will be further processed.

- The flood hazard maps, the flood risk maps - show the potential adverse consequences associated with different flood scenarios, including information on potential sources of environmental pollution as a consequence of floods.

- The flood risk management plans - It should focus on prevention, protection and preparedness. The elements of flood risk management plans should be periodically reviewed and if necessary updated, taking into account the likely impacts of climate change on the occurrence of floods.

\subsection{Legal Framework}

In the Czech Republic flood protection is in focus of many legislative documents. The pivotal one is the Act of 28 June 2001 on Water and Amendments to Some Acts (The Water Act), which defines flood prevention, floodplain zones, flood activity degrees, flood plans, flood inspections, flood prediction services, rescue activities etc. Beside this Act, there is a huge number of other important legislative regulations settled in another Acts. They are concerned with, e.g.: 
- definition of crises situations, crises management bodies and financial issues (Act No. 240/2000),

- determination of cooperation among Integrated Rescue System units, definition of their tasks and roles (Act No. 239/2000)

- definition of military assistance in the case of extraordinary event (Act No. 219/1999)

- definition of public administration competencies (Act No. 128/2000)

- specification of life, health and property protection in the case of disaster events (Act No. 133/1985)

- specification of the state subsidy in the case of disaster event (Act No. 363/1999).

Protection itself is secured according to Flood Management Plans and, in the case that crisis situation is declared, according to Crises and Emergency Plans. Protection against the natural floods is controlled by Flood Authorities that are (on territorial basis) responsible for organization of flood prevention and response; further they administer and coordinate the activities of other responsible actors within flood prevention and response. Character and activity of Flood Authorities are specified for two periods - beyond flood and during flood; their specification in hierarchical order is shown in Table 1.

Table 1. Flood Authorities beyond and during flood on different hierarchical levels

\begin{tabular}{|l|l|l|}
\hline & Beyond flood & During flood \\
\hline Municipality level & Municipality authorities & $\begin{array}{l}\text { Flood Staff of the } \\
\text { Municipality }\end{array}$ \\
\hline District level & $\begin{array}{l}\text { Authorities of the } \\
\text { Municipalities with Extended } \\
\text { Powers }\end{array}$ & $\begin{array}{l}\text { Flood Staff of the } \\
\text { Municipalities with Extended } \\
\text { Powers }\end{array}$ \\
\hline Regional level & Regional authorities & Flood Staff of the Region \\
\hline State level & $\begin{array}{l}\text { Ministry of the Environment } \\
\text { Ministry of the Interior }\end{array}$ & Central Flood Staff \\
\hline
\end{tabular}

\subsection{Activities in the Flood Management}

Flood management is very complex set of tasks. Flood Authorities are responsible of coordination of activities of different user groups. It includes e.g. units of the Integrated Rescue System (Fire Rescue Service of the Czech Rep., Police of the Czech Rep., Ambulance Service etc.), River Basin Districts Authorities, Watercourse managers, etc. These users are responsible for different tasks in flood management; some of them can (or must) be supported by geoinformation.

Watercourse managers and managers of touched object (or other subjects ordered by Flood Authorities) are responsible for Flood Security Activities (e.g. measures against water pollution, removing blockades of ice) that must be coordinated with the River Basin Authorities. Fire Rescue Service (FRS) as one of the component of Integrated Rescue System (IRS) has many tasks within Flood Rescue Activities (e.g. evacuation, rescue of citizens), Flood Security Activities (e.g. flood survey, indication of dangerous areas) and Organizational Activities (e.g. coordination of rescue works). 
Flood Authorities are responsible for planning (e.g. compilation of Flood Plan), organizing (e.g. local early warning), and securing (e.g. health care and emergency supply).

\section{Flood Related Spatial Data and Services to Support Activities within the Disaster Management Cycle}

In the following chapters we will review existing geospatial support for prevention activities (Risk Assessment), preparation activities (Pre-impact activities) and response activities (Emergency management).

\subsection{Geoinformation for Prevention - Flood Zone Mapping, Insurance Maps, Flood Risk Mapping}

The main role of geospatial support within this particular part of cycle is to identify the potential areas of risk and minimise future losses of both lives and assets.

According The Water Act (No. 254/2001) Flood zone is an area that can be flooded during the natural flood event. Its extent is proposed by the particular watercourse manager for discharges occurring once per 5/20/100 years. Its delimitation is given by Legal notice No. 236/2002 and is based e.g. on hydrological data, on regulations of water structures influencing flood discharges, on longitudinal and cross sections of the river etc. Project of flood zone is elaborated on the ground map of the Czech Republic 1:10 000. Besides the flood zone also Active zone of flood area is determined. It is an urban area that influences drainage during floods.

Almost all property insurances in the Czech Republic use Flood Risk Assessment Tool (FRAT) developed by Swiss Re to identify high exposed risks. Users can be located by the address (street, house number, and city) or interactively on the map. The system generates information on the flood risk exposure of the selected location and displays it on-screen. The tool distinguishes four different flood risk zones: Zone 1: very low flood risk, Zone 2: low flood risk, Zone 3: medium flood risk, Zone 4: high flood risk. The insurance flood zones database is available not only for the main watercourses but also for local streams with drainage basin larger than $20 \mathrm{sq} \mathrm{km}$.

The Czech Republic adopted the Flood Directive 2007 and proposed the national methodology for flood mapping. The methodology is based on matrix of risk [1] and is closely connected to the standard database established, operated and administrated within the Czech water management. It comprises following main procedures: identification of the flood hazard, determination of vulnerability and semi-quantitative implication of flood risk by four-degree scale. The final methodology result is flood risk map combining information about danger and vulnerability of objects and activities in the floodplain. Landscape vulnerability is represented by objects and activities occurring in landscape. Resulting flood risk zones show areas where maximal acceptable risk is exceeded. The reached values of the flood danger in the corresponding colour scale are indicated inside each such highlighted area. For detail description of the corresponding methodology see [7]. 


\subsection{Geoinformation for Preparation - Integrated Warning Service System, Flood Modelling}

Preparation or pre-disaster phase is characterised by a combination of warning services and spatially depending flood forecasts initiating the whole set of activities. Integrated Warning Service System (IWSS), a component of Integrated Rescue System of the Czech Republic, is meteorology and hydrology warning service for the Czech Republic. IWSS is provided jointly by Central Forecasting Office (CPP) of the Czech Hydrometeorological Institute (CHMI) [2] (within Ministry of the Environment) and the Department of Hydrometeorological Services of the Military Geographical and Hydrometeorological Office (within Ministry of Defence). IWSS provides evaluation of up-to-date meteorological and hydrological data, information and forecasts and delivering integrated warning information. The part of Central Forecasting Office (CPP) is Warning and Information Office; its main activity is to alert in the case of dangerous meteorological phenomena (e.g. heavy rain, snow cover, snowdrift, strong wind, frost in vegetation time) and other weather phenomena (smog, dangerous air substance transmission etc.).

Czech Hydrometeorological Institute (CHMI) employs two hydrological models for discharge prediction - HYDROG and AQUALOG.

HYDROG is rainfall-runoff model for flood simulations and discharge prediction. Inputs are discharges, controlled water reservoirs run-offs and precipitation; in winter also data about temperature and snow cover.

AQUALOG is programming tool for simulation, prediction and run-off management and water quality in real time and in the past. It allows numeric simulations of creation and melting of snow cover, rainfall-runoff transformation, simulation and management on reservoirs, and modelling of diffuse processes on surface waters.

\subsection{Geoinformation for Response - Flood Management Plan}

When flood becomes a reality than it is necessary to follow certain strategy in order to minimise the potential flooding impact. Flood Management Plans are sources of information for this part of disaster cycle. The Flood Management Plan is divided to factual, organisational, and graphic parts.

Factual part includes information necessary for securing specific object, municipality, complex basin or other territory, directive limits for declaration of degrees of flood activity, informs about the possibilities to influence discharge, etc. Organisational part includes list of names and addresses, describes communication links between involved persons, specify tasks for people and organization concerned with flood protection, assists with securing local early warning system etc. Graphic part includes following maps: Flood Committees \& Evacuation Places, Gauging stations \& Precipitation Station, Flood areas, Watercourse and water structures, Transportation.

There are four types of Flood Management Plans (FMP) corresponding with hierarchical order of flood authorities - FMP of the Czech Republic, FMP of the Region, FMP of the Municipalities with Extended Powers, FMP of the Municipality and the fifth one (Other Flood Management Plan) that is done for the buildings and parcels that either lay in the floodplain or can influence the progress of the flood. 


\section{Adaptive Mapping in Crisis Management}

Chapter 3 documented exiting sources of geoinformation and services related to floods. Flood management plans offers set of analytical maps; they are sources of essential information but in time limited situations in preparation and response phase may be not effective. They are thematically oriented (e.g. transportation, gauging stations) but not task oriented. Existing maps have predominantly information function, i.e. it inform about "what is where". But modern cartography can offer more; it can shift map to decision-making tool. So called adaptive mapping [9] brings to crisis management opportunity to be more effective by adaptation of cartography outputs to needs of users. User is supplied only by the information that is necessary for decision making and is given in the most comprehensive form for the user. Context in which the geographic data are presented plays the key role; thus the term context cartography is also used. Cartography visualization (e.g. map) is adapted to user's context. Context is the set of characteristics dealing with the user, environment and the purpose $[9,8,14,5]$.

The aim of adaptive mapping is to facilitate different users to work over the same data. Even though the context maps portray the same objects and phenomena, the knowledge the users get from it depends on the task they are responsible for. The visualization reflects the role the object plays in decision making process, e.g. object school play different roles in task of flood prediction and in task of navigation. In the former case, the maps supply the knowledge about the "object of social character with people that need special protection". In the later, the school plays the role of "object that eases orientation". Cartography model for each context map must reflect this fact; different roles of the same object in reality are expressed by different map symbols and in different implications.

\subsection{Conceptual Framework - Study "FLOOD"}

Our approach followed the idea of [5] and modified it with the respect to cartography visualization in crisis management.

Context is the set of factors that influence legibility and usability of the map [9]. There is an indefinite number of such factors and thus it is necessary to chose those with the highest influence.

We distinguish three main context types:

1. Identity context. This type of context refers to questions like "Who will use the map? Who is responsible for what?". This context influences the visualization since users having diverse professional background are using different visualization methods and map symbols. Further, this information is used for authorization rights purposes, i.e. which data (data layers, properties) can be managed and administered by the user. For example POLICE can edit information about roads, watercourse managers about objects on the river, etc.

2. Functional context. It deals with questions "How the map will be used? What is the function of the map in the decision making process? We can distinguish three groups of users: users that only needs to know "what is where" - function INFO), user that needs to update status of spatial objects (e.g. bridge is destroyed, road is 
closed) - function CONTROL, and users who need to create new object (e.g. place where intervention is necessary, place of ice blockage) - function ORGANIZE.

3. Emergency core context. It is the most complex one. It refers to the issue of data content. Within it two particular questions are dealt: What? and When?

Question WHAT? implies the ACTIVITY, e.g. What activity should be supported with the map? Activity embodies the range of tasks that the user is responsible for. It is the most crucial factor that determinates the specific view of the reality; by familiarity with the knowledge that user must get to be able to perform decision making it is possible to guess about relevance of spatial object and thus to define map content. Following five main activities were defined for the event FLOOD:

- PREDICTION AND PROGRESS - development and expected progress of the flood

- TECHNICAL SUPPORT - technical support in inundation area - support of Flood Security Activities

- RESCUE - evacuation of the citizens

- ORGANIZATION - organization of power and means

- PUBLIC INFORMATION - information for public about flood development, evacuation etc.

Question WHEN? specifies the STAGE, e.g. In what phase of the emergency event the activity is realised? The crisis management is not limited to the response phase of the event but pass the entire disaster management circle. We can specify four phases of crisis management circle [11] that correspond to the four STAGES:

- prevention (out of the flood)

- preparation (shortly before the flood)

- response (during the flood)

- recovery (after the flood)

Figure 1 illustrates which emergency core contexts are defined based on the activity and the stage. For example, to realize the activity rescue in preparation phase user chose the context evacuation preparation for which data content is defined.

Activity and stage are parameters that primarily define map content, e.g. what should be on the map. The other parameter is OPERATIONAL RANGE that relates to WHERE? and deals with questions like Where the event takes place? What is the event extent? What is the activity extent? This parameter does not influence the map content "thematically" but tackle the problem how many information can be portrayed on the map so that it is still legible. It influences character of generalization; it must be not only quantitative but also semantically based.

Five basic operational ranges were defined:

- one for detailed information - e.g. part of floodplain: $L O C A L$

- three due to hierarchical system of flood management: REGION, DISTRICT, MUNICIPALITY

- one due to the necessity to flood monitoring in natural borderlines: CATCHMENT

Map scale of the corresponding operational range spans from large (i.e. 1:5 000 - 1:2 000) for LOCAL to small (i.e. 1:500 000 - 1: 1 mil.) for REGION and CATCHMENT to capture appropriate (administrative or natural) unit. Operational range is 


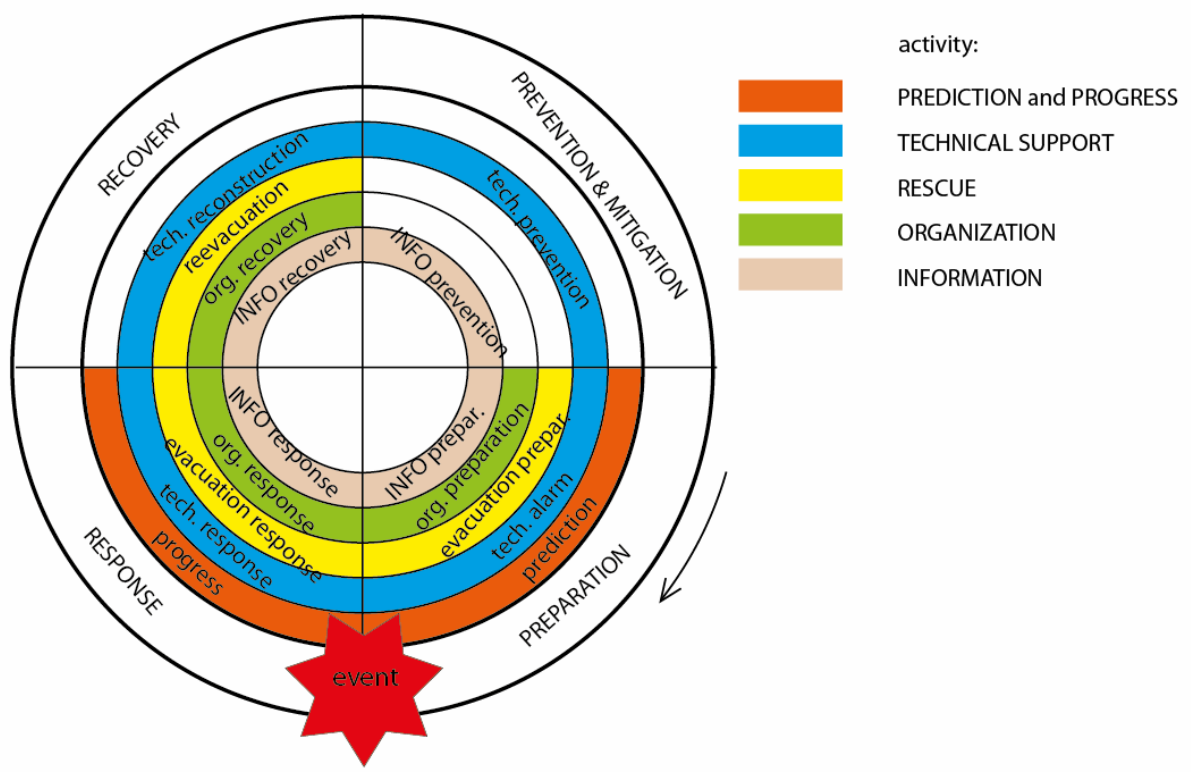

Fig. 1. Emergency core context definition within disaster management circle

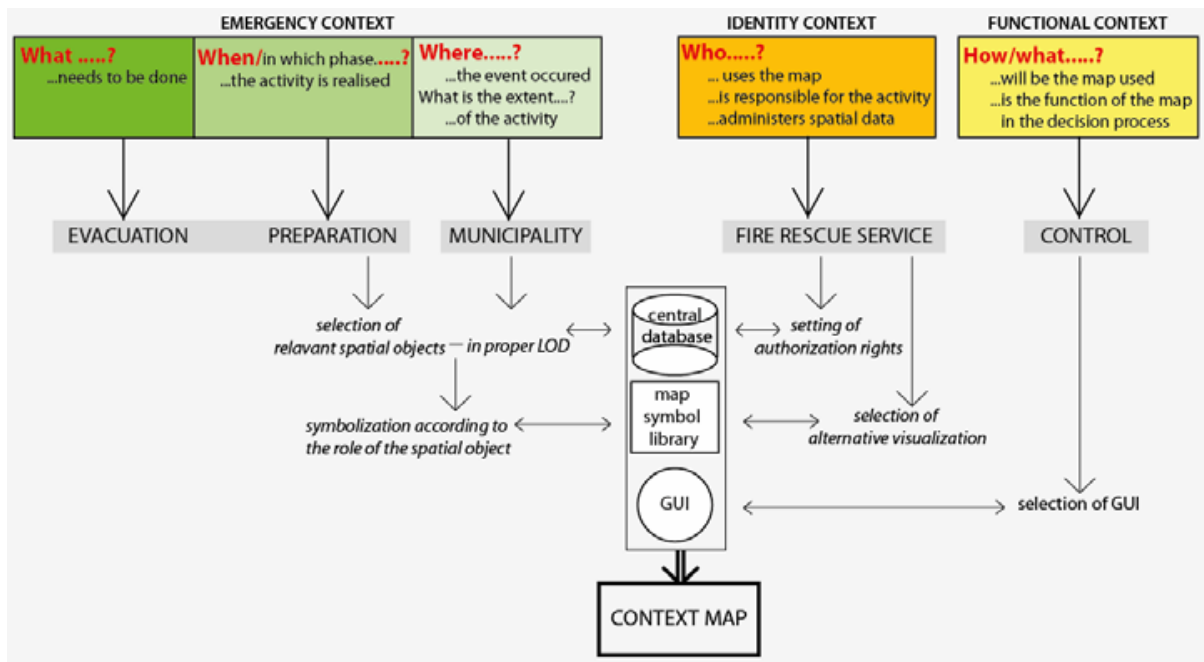

Fig. 2. Context map composition

assigned to each emergency core context and defines in which level of detail information will be (most probably) used. Users are not limited to work in the dedicated operational range but out of it they may get less information. 


\subsection{Context Composition}

Appearance and functionality of final context map will be set by the combination of all particular contexts: identity, functional and core emergency. The user can define, for example, the context map by the following profile:

\section{Identity context: Fire Rescue Service \\ Functional context: control \\ Emergency core context: evacuation + preparation}

Content of the invoked map will be to ensure the evacuation (emergency accommodation, access roads etc.), symbology and access rights for fire rescue service will be called out and GUI will allow editing of attributes (e.g. user can change the status of evacuated building to evacuation terminated). Process of context map composition is illustrated on figure 2 .

\section{Conclusion}

Paper described state of the art within flood case of emergency management cycle and has shown a wide variety of both users' requirements and available geoinformation sources. In accordance with [6] and [10] we can conclude that intuitive interfaces and dynamic visualization are highly demanded. Thus the adaptive cartographic visualization with simple associative icons and symbols can significantly improve the communication. [15] documented that an adaptive cartographic (context based) approach applied for integrated rescue system operators led to lighter maps which were more efficient than existing overloaded multipurpose maps. In the next phase we plan to fully implement the adaptive approach for a selected flood management area and consequently test the cognitive issues for selected tasks within the emergency cycle.

\section{References}

1. Beffa, C.: A Statistical Approach for Spatial Analysis of Flood Prone Areas. In: International Symposium on Flood Defence, D-Kassel, p. 8 (2000)

2. Czech Hydrometeorogical Service, http: / / www . chmi . cz

3. Committee on Planning for Catastrophe: Successful Response Starts with a Map: Improving Geospatial Support for Disaster Management, p. 197 (2007)

4. COUNCIL OF THE EUROPEAN UNION: DIRECTIVE 2007/60/EC OF THE EUROPEAN PARLIAMENT AND OF THE COUNCIL of 23 October 2007 on the assessment and management of flood risks (2007)

5. Dey, A.K., Abowd, G.D.: Towards a better understanding of context and contextawareness. In: Proceedings of the CHI 2000 Workshop on The What, Who, Where, When, and How of Context-Awareness, The Hague, Netherlands (2000)

6. Diehl, S., Neuvel, J., Zlatanova, S., Scholten, H.: Investigation of user requirements in the emergency response sector: the Dutch case. In: Proceedings of the Second Gi4DM, Goa, India, CD ROM, September 25-26, p. 6 (2006) 
7. Drbal, K., Dráb, A., Friedmannová, L., Horský, M., Levitus, V., Ř́íha, J., Satrapa, L., Štěpánková, P., Valenta, P.: The Methodology for the Flood risks and Flood hazards map making. Bulletin of the Ministry of the Environment XX(4), 4-70 (2010) (in Czech)

8. Erharuyi, N., Fairbairn, D.: Task-Centred Adaptation of Geographic Information to Support Disaster Management. In: van Oosterom, P., Zlatanova, S., Fendel, E.M. (eds.) Geoinformation for Disaster Management, pp. 997-1008. Springer, Heidelberg (2005)

9. Friedmannová, L., Konečný, M., Staněk, K.: Adaptive maps for crises management. Kartografické Listy 15, 41-50, 127 (2007)

10. Kubíček, P., Ludík, T., Mulíčková, E., Ráček, J., Šafr, G.: Process Support and Adaptive Geovisualisation in Emergency Management. In: Geographic Information and Cartography for Risk and Crisis Management - Towards Better Solutions, 1st edn. Lecture Notes in Geoinformation and Cartography, pp. 335-348, 14. Springer, Heidelberg (2010)

11. Lumbroso, D., et al.: Review report of operational flood management methods and models, FLOODsite Project Report No. T17-07-01 (2007)

12. Mulíčková, E., Šafr, G., Staněk, K.: Context map - a tool for cartography support in crisis management. In: 3rd International Conference on Cartography and GIS, Nessebar (2010)

13. Pequet, J.: A Conceptual Framework and Comparison of Spatial Data Models. Cartographic Journal 2(4), 66-113 (1984)

14. Reichenbacher, T.: Adaptive Methods for Mobile Cartography. In: The 21st International Car-tographic Conference Durban 2003, Proceedings on CD-ROM (2003)

15. Staněk, K., Friedmannová, L., Kubíček, P., Konečný, M.: Selected issues of cartographic communication optimization for emergency centers. International Journal of Digital Earth 3(4), 316-339 (2010) 